\title{
Sport-Related Concussion and Neuropsychological Testing: Shaken or Stirred?
}

\section{Vaishali Sisodia ${ }^{1}$ and Senthil P Kumar ${ }^{2 *}$}

${ }^{1}$ Post-graduate Student, Srinivas College of Physiotherapy and Research Centre, Mangalore, India

${ }^{2}$ Professor, Maharishi Markandeshwar Institute of Physiotherapy and Rehabilitation (MMIPR), Maharishi Markandeshwar University (MMU), Mullana (Ambala), India

\begin{abstract}
Concussion is a traumatically induced transient disturbance of brain function and involves a complex pathophysiological process at the less-severe end of brain injury spectrum. Sport-Related Concussion (SRC) is increasingly been recognized as an individual entity globally. Whilst the neurological effects of SRC are well known, neuropsychological testing and its implications in SRC remain to elude sports medicine professionals with a dilemma of to do or not do? This editorial aimed to address this issue speculating from an evidence-informed viewpoint. An overview of definition, history and development of neuropsychological testing, its uses and issues related to its interpretation are discussed in this paper, with implications for future research.
\end{abstract}

\section{Definition}

American Medical Society for Sports Medicine(AMSSM) defined Concussion "as a traumatically induced transient disturbance of brain function and involves a complex pathophysiological process, which is a subset of Mild Traumatic Brain Injury (MTBI) and is generally selflimited and at the less-severe end of the brain injury spectrum [1]." Prevalence of Sport-Related Concussion (SRC) varies depending upon type of sport, but is eventually occurring in all types of sport especially more so in football, soccer, and baseball [2].

\section{History and Development}

The earliest understanding of SRC as an acceleration-deceleration injury was explained by using the model of Newtonian Physics to objectively measure the forces applied to the brain during accelerationdeceleration injuries, and to predict functional outcome, such as neurocognitive status, recovery curves, and return to play from the obtained data $[3,4]$.

From the bench to the bedside, the evidence points out both basic science and clinical controversies existed in SRC where the former included labeling the condition as a 'functional brain injury' rather than structural or pathological brain damage, while the latter involved issues with definition, injury severity grading, classification, and understanding of clinical symptoms and motor/convulsive squeal [5].

\section{Evaluation of Concussion}

Evaluation of symptom severity, neuro cognitive function and postural stability forms a comprehensive part of assessment of sportspersons with concussion [6]. However, a plethora of diagnostic measures were reported in literature namely; structural imaging (computerized tomography, magnetic resonance imaging, diffusion tensor imaging), functional imaging (single photon emission computerized tomography, positron emission tomography, functional magnetic resonance imaging), spectroscopy (magnetic resonance spectroscopy, near infrared spectroscopy), balance testing (Balance Error Scoring System, Sensory Organization Test, gait testing, virtual reality), electrophysiological tests (electroencephalography, evoked potentials, event related potentials, magneto encephalography, heart rate variability), genetics (apolipoprotein E4, channelopathies) and blood markers (S100, neuron-specific enolase, cleaved Tau protein, glutamate) [7].

\section{Treatment of Concussion}

Treatments for SRC ranged from rest and removal from sports participation, followed by low level exercise and multimodal physiotherapy, later followed by active rehabilitation during returnto-sport phase $[8,9]$. Clinical outcomes for SRC included generic and specific outcomes instruments aimed at assessing general health-related quality of life or various concussion symptoms and co morbidities such as headache, migraine, fatigue, mood disturbances, depression, anxiety, and concussion-related symptoms [10].

\section{Uses of Neuropsychological Testing}

Neuropsychological assessment provides not only an objective method for evaluation of SRC, but also its associated individual-related factors such as age, gender, and history of prior concussion [11]. Neuropsychological findings in SRC include difficulties in attention and concentration, speed of information processing and impaired memory [12]. Neuropsychological testing had evolved from use of paper-andpencil tests, to conducting field tests of balance and much later, to the most widely marketed computer-based test batteries, however the diagnostic implications are far more reliable than from a prognostic viewpoint [13].

Despite the lack of high quality evidence for neuropsychological test methods for use in SRC, many sports medicine physicians, athletic trainers, physical therapists, coaches and athletes use these tests and they are mandated by several professional sports academies and societies' guidelines [14]. Current practice and education in the field of sports medicine revolves around professionals' belief in NP testing as a simple to use on-field measurement method [15].

\section{Issues with Neuropsychological Testing}

Baseline neuropsychological screening using Impact test was questioned for its reliability and validity, and was not likely to

\footnotetext{
*Corresponding author: Senthil P Kumar, Maharishi Markandeshwar Institute of Physiotherapy and Rehabilitation (MMIPR), Maharishi Markandeshwar University (MMU), Mullana (Ambala), India, Tel: 00919341963889; E-mail: senthil.p.kumar@mmumullana.org

Received November 25, 2013; Accepted November 25, 2013; Published November 29, 2013

Citation: Vaishali S,Senthil PK (2013) Sport-Related Concussion and Neuropsychological Testing: Shaken or Stirred? J Sports Med Doping Stud 3: e138. doi:10.4172/2161-0673.1000e138

Copyright: ( $) 2013$ Vaishali S, et al. This is an open-access article distributed under the terms of the Creative Commons Attribution License, which permits unrestricted use, distribution, and reproduction in any medium, provided the original author and source are credited.
} 
diminish the risk of SRC, and since there is so much risk associated with premature return to play that the test itself might increase risk in some situations [16]. Recently identified six key issues in sports-related neuropsychological assessment in concussion: "(1) the advantages and disadvantages of different neuropsychological assessment modalities; (2) the evidence for and against the current paradigm of baseline/postinjury testing; (3) the role of psychological factors in the evaluation and management of concussion; (4) advances in the neuropsychological assessment of children; (5) multi-modal assessment paradigms; (6) the role of the neuropsychologist as part of the sports healthcare team and (6) the appropriate administration and interpretation of neuropsychological tests [17].”

\section{Final Points}

AMSSM summarized their stand on NP testing in SRC as follows; "Neuropsychological (NP) tests are an objective measure of brain-behavior relationships and are more sensitive for subtle cognitive impairment than clinical exam. Most concussions can be managed appropriately without the use of NP testing. Computerised Neuropsychological (CNP) testing should be interpreted by healthcare professionals trained and familiar with the type of test and the individual test limitations, including a knowledgeable assessment of the reliable change index, baseline variability and false-positive and false-negative rates. Paper and pencil NP tests can be more comprehensive, test different domains and assess for other conditions which may masquerade as or complicate assessment of concussion. NP testing should be used only as part of a comprehensive concussion management strategy and should not be used in isolation. - The ideal timing, frequency and type of NP testing have not been determined. - In some cases, properly administered and interpreted NP testing provides an added value to assess cognitive function and recovery in the management of sports concussions. It is unknown if use of NP testing in the management of sports concussion helps prevent recurrent concussion, catastrophic injury or long-term complications. - Comprehensive NP evaluation is helpful in the post-concussion management of athletes with persistent symptoms or complicated courses [1]."

American Academy of Clinical Neuropsychology (AACN), American Board of Professional Neuropsychology (ABN), Division 40 (Neuropsychology) of the American Psychological Association (APA), and the National Academy of Neuropsychology (NAN) stated that neuropsychologists should be included among the licensed healthcare professionals authorized to evaluate, clinically manage, and provide return to play clearance for athletes who sustain a SRC [18].'

\section{For the Future}

Quantitative Electroencephalographic (Q-EEG) measurements and assessment of neurocognitive function had been shown to predict an accurate return to sport decision compared to clinical symptoms or field tests [19]. Future research should incorporate such methods in order to establish predictive validity of NP tests in this sports population.

"Coming to the answer: yes, NP testing in SRC continues to be stirred by theoretical rationale and practical utility yet shaken by the era evidence-informed sports medicine."

\section{References}

1. Harmon KG, Drezner JA, Gammons M, Guskiewicz KM, Halstead M (2013) American Medical Society for Sports Medicine position statement: concussion in sport. Br J Sports Med 47: 15-26.
2. Daneshvar DH, Nowinski CJ, McKee AC, Cantu RC (2011) The epidemiology of sport-related concussion. Clin Sports Med 30: 1-17.

3. Barth JT, Freeman JR, Broshek DK, Varney RN (2001) AccelerationDeceleration Sport-Related Concussion: The Gravity of It All. J Athl Train 36 253-256.

4. McCrory P, Johnston KM, Mohtadi NG, Meeuwisse W (2001) Evidence-based review of sport-related concussion: basic science. Clin J Sport Med 11: 160 165

5. Johnston KM, McCrory P, Mohtadi NG, Meeuwisse W (2001) Evidence-Based review of sport-related concussion: clinical science. Clin J Sport Med 11: 150159

6. 6. Guskiewicz KM (2003) Assessment of postural stability following sportrelated concussion. Curr Sports Med Rep 2: 24-30.

7. Davis GA, Iverson GL, Guskiewicz KM, Ptito A, Johnston KM (2009) Contributions of neuroimaging, balance testing, electrophysiology and blood markers to the assessment of sport-related concussion. $\mathrm{Br} \mathrm{J}$ Sports Med 1 : i36-45.

8. Schneider KJ, Iverson GL, Emery CA, McCrory P, Herring SA, et al. (2013) The effects of rest and treatment following sport-related concussion: a systematic review of the literature. $\mathrm{Br} \mathrm{J}$ Sports Med 47: 304-307.

9. Gagnon I, Galli C, Friedman D, Grilli L, Iverson GL (2009) Active rehabilitation for children who are slow to recover following sport-related concussion. Brain Inj 23: 956-964.

10. Valovich McLeod TC, Register-Mihalik JK (2011) Clinical outcomes assessmen for the management of sport-related concussion. J Sport Rehabil 20: 46-60.

11. Johnson EW, Kegel NE, Collins MW (2011) Neuropsychological assessment of sport-related concussion. Clin Sports Med 30: 73-88.

12. Taylor AM (2012) Neuropsychological evaluation and management of sportrelated concussion. Curr Opin Pediatr 24: 717-723.

13. Randolph C, McCrea M, Barr WB (2005) Is neuropsychological testing useful in the management of sport-related concussion? J Athl Train 40: 139-152.

14. Grindel SH, Lovell MR, Collins MW (2001) The assessment of sport-related concussion: the evidence behind neuropsychological testing and management. Clin J Sport Med 11: 134-143.

15. Covassin T, Elbin R 3rd, Stiller-Ostrowski JL (2009) Current sport-related concussion teaching and clinical practices of sports medicine professionals. Athl Train 44: 400-404

16. Randolph C (2011) Baseline neuropsychological testing in managing sportrelated concussion: does it modify risk? Curr Sports Med Rep 10: 21-26.

17. Echemendia RJ, Iverson GL, McCrea M, Macciocchi SN, Gioia GA, et al. (2013) Advances in neuropsychological assessment of sport-related concussion. $\mathrm{Br} \mathrm{J}$ Sports Med 47: 294-298.

18. Echemendia RJ, Iverson GL, McCrea M, Broshek DK, Gioia GA et al. (2012) Role of neuropsychologists in the evaluation and management of sport-related concussion: an inter-organization position statement. Arch Clin Neuropsycho 27: 119-122.

19. McCrea M, Prichep L, Powell MR, Chabot R, Barr WB (2010) Acute effects and recovery after sport-related concussion: a neurocognitive and quantitative brain electrical activity study. J Head Trauma Rehabil 25: 283-292. 